\title{
Comparison of nebulized glycopyrrolate and metaproterenol in chronic obstructive pulmonary disease
}

\author{
G. Tzelepis, S. Komanapolli, D. Tyler, D. Vega, A. Fulambarker
}

\begin{abstract}
Comparison of nebulized glycopyrrolate and metaproterenol in chronic obstructive pulmonary disease. G. Tzelepis, S. Komanapolli, D. Tyler, D. Vega, A. Fulambarker. ( $E R S$ Journals Ltd 1996.

ABSTRACT: We assessed the bronchodilating effect of glycopyrrolate (GP) and compared it with that of metaproterenol (MP), alone and in combination (GP+MP), in patients with chronic obstructive pulmonary disease (COPD).

In a double-blind study, 11 patients (aged (mean $\pm \mathrm{SD}) 69 \pm 6$ yrs; forced expiratory volume in one second $(F E V 1) 1.2 \pm 0.4 \mathrm{~L}$ ) with stable COPD inhaled nebulized GP $1.0 \mathrm{mg}$, MP $15 \mathrm{mg}$, or GP $1.0 \mathrm{mg}+$ MP $15 \mathrm{mg}$. Spirometry was performed before inhalation and at hourly intervals for $8 \mathrm{~h}$ after inhalation.

It was found that GP produced a bronchodilating effect that was about equal to that of MP but lasted longer ( 8 vs $5 \mathrm{~h}$ ). The combination of GP and MP produced a bronchodilating effect that was greater than that of either drug alone and was evident mostly during the effect of MP. The mean peak percentage improvement in FEV1 over baseline was $35 \%$ for GP+MP and $25 \%$ for either drug alone.

These data suggest that nebulized glycopyrrolate is an effective bronchodilator in some patients with chronic obstructive pulmonary disease. Concurrent administration of glycopyrrolate and metaproterenol produces additional bronchodilation that is primarily apparent during the bronchodilator effect of metaproterenol. Eur Respir J., 1996, 9, 100-103.
\end{abstract}

Glycopyrrolate (GP), a quarternary ammonium compound, is an anticholinergic agent that has primarily been used with anaesthesia to reduce gastric acidity and salivary secretions or to reverse neuromuscular blockade [1]. Recently, GP has been used as a bronchodilator in patients with asthma [2-5]. This study was designed to investigate the bronchodilator effect of GP in patients with stable chronic obstructive pulmonary disease (COPD) and compare it with that of another commonly used bronchodilator, the $\beta$-adrenergic agonist metaproterenol (MP). In addition, we examined whether the concurrent administration of GP and MP provided any further bronchodilation than GP alone in this group of patients.

\section{Methods}

Eleven men with diagnoses of chronic bronchitis, emphysema, or both [6] were recruited from out-patient pulmonary clinics to participate in the study (table 1). Stability of their disease was defined as no hospitalizations or change in therapy over a 6 month period prior to the study. All patients had a forced expiratory volume in one second/forced vital capacity ratio (FEV1/FVC) of less than $70 \%$, and a history of cigarette smoking. A positive bronchodilator response following inhalation of metaproterenol, as defined by the American Thoracic Society (ATS) criteria [6], was documented during previous pulmonary function testing. None of the subjects had a history of bronchial asthma or were on oral steroids. The study was approved by the institutional review committee and informed consent was obtained from all patients.

Measurements of FVC and FEV1 were performed on a Collins Eagle One spirometer (Braintree, MA, USA). The medications were mixed with normal saline to a total volume of $7.5 \mathrm{~mL}$ and aerosolized using a Misty-Neb nebulizer (Airlife) with a flow rate of $10 \mathrm{~L} \cdot \mathrm{min}^{-1}$ delivered over $15 \mathrm{~min}$. GP, MP, or both were administered randomly and in double-blind fashion. Theophylline preparations and beta-agonists were discontinued 24 and $12 \mathrm{~h}$ prior to each study day, respectively. The subjects were studied in the pulmonary function laboratory on three separate days, at least three days apart. On each study day, baseline measurements of FEV1 and FVC were obtained followed by inhalation of one of the following aerosols: 1) GP $1.0 \mathrm{mg}$; 2) MP $15 \mathrm{mg}$; or 3) GP $1.0 \mathrm{mg}$ and MP $15 \mathrm{mg}$. Measurements of FVC and FEV1 were subsequently performed at hourly intervals for $8 \mathrm{~h}$. Blood pressure and pulse rate were measured before treatment and at the time of spirometry. Subjects were also questioned about any side-effects.

The largest FVC and FEV1 of at least three reproducible values, as measured according to ATS standards [6], were analysed. The FEV1 and FVC data were subjected to analysis of covariance (ANCOVA), where the drug regimen (drug) and time were within-subject variables and baseline performance was a covariate that was 
Table 1. - Patient characteristics and pulmonary function testing data

\begin{tabular}{lccccccccc}
\hline $\begin{array}{l}\text { Pt } \\
\text { No. }\end{array}$ & $\begin{array}{c}\text { Age } \\
\text { yrs }\end{array}$ & $\begin{array}{c}\text { Smoking Hx } \\
\text { pack-yrs }\end{array}$ & $\begin{array}{c}\text { FEV } 1 \\
\text { L }\end{array}$ & $\begin{array}{c}\text { FEV } 1 \\
\% \text { pred }\end{array}$ & $\begin{array}{c}\Delta \text { FEV } 1 \\
\% \text { init }\end{array}$ & $\begin{array}{c}\Delta \text { FEV } 1 \\
\% \text { pred }\end{array}$ & $\begin{array}{c}\text { FVC } \\
L\end{array}$ & $\begin{array}{c}\text { TLC } \\
\text { L }\end{array}$ & $\begin{array}{c}\text { TLC } \\
\% \text { pred }\end{array}$ \\
\hline 1 & 70 & 56 & 0.84 & 21 & 21 & 5 & 1.8 & 6.4 & 101 \\
2 & 60 & 60 & 1.26 & 44 & 23 & 10 & 2.6 & 6.4 & 106 \\
3 & 63 & 98 & 0.58 & 19 & 15 & 3 & 1.3 & 7.2 & 115 \\
4 & 59 & 120 & 1.53 & 46 & 22 & 10 & 3.2 & 6.3 & 97 \\
5 & 68 & 50 & 0.81 & 24 & 25 & 6 & 1.7 & 6.2 & 90 \\
6 & 75 & 26 & 1.18 & 35 & 33 & 11 & 2.1 & 8.5 & 118 \\
7 & 70 & 92 & 1.46 & 46 & 26 & 11 & 2.9 & 7.2 & 108 \\
8 & 72 & 110 & 0.87 & 26 & 16 & 4 & 1.7 & 6.8 & 199 \\
9 & 70 & 46 & 1.99 & 61 & 19 & 11 & 3.3 & 6.9 & 96 \\
10 & 70 & 92 & 0.86 & 32 & 18 & 4 & 1.8 & 7.9 & 122 \\
11 & 80 & 67 & 1.82 & 70 & 11 & 9 & 3.1 & 6.4 & 115 \\
\hline Mean & 69 & 74 & 1.2 & 38 & 21 & 8 & 2.3 & 6.9 & 108 \\
\pm SD & \pm 6 & \pm 30 & \pm 0.4 & \pm 17 & \pm 6 & \pm 3 & \pm 0.7 & \pm 0.7 & \pm 11 \\
\hline
\end{tabular}

Pt: patient; Hx: history; FEV1: forced expiratory volume in one second; $\%$ pred: percentage of predicted normal value; $\triangle \mathrm{FEV} 1$ : change in FEV1 in response to metaproterenol; \% init: percentage of initial FEV1; FVC: forced vital capacity; TLC: total lung capacity.

constant across time but changing across drug. Since the sphericity hypothesis was rejected (for both dependent variables), Greenhouse-Geisser probabilities are reported where appropriate. In addition, repeated measures analysis of variance (ANOVA) for single within-subject variable (drug) at each interval was performed for both FEV1 and FVC data. A p-value $<0.05$ was considered to be statistically significant. All analyses were performed using the BMDP statistical program (Los Angeles, CA, USA) [7].

\section{Results}

Subject characteristics and baseline pulmonary function data are shown in table 1 . Reversibility for the group was $8 \pm 3 \%($ mean \pm SD) of predicted FEV1. The ANCOVAs revealed significant effects for the covariate, drug, time, and drug-by-time interaction both for FEV1 $(p<0.01)$ and FVC $(p<0.05)$. Thus, performance following treatment was shown to be affected by baseline (pretreatment) performance, the drugs administered, and the time after administration. Furthermore, though there were overall drug effects, the magnitude of differences between drugs varied over time (drug-by-time interaction).

Figure 1 presents mean values for FEV1 measured at each time interval for all regimens. In comparing the overall drug effects, GP was more effective than MP $(\mathrm{p}<0.05)$, and the combination of GP and MP was more effective than either drug alone $(\mathrm{p}=0.014$ for GP; and $\mathrm{p}=0.0016$ for MP). Further analysis at each time period showed that GP and MP produced similar improvements in FEV1 at 1-5 h; thereafter, the improvements in FEV1 were greater with GP (approximately $13 \%$ above baseline) than with MP $(\mathrm{p}<0.05)$. The combination of GP and MP produced an improvement in FEV1 that was significantly higher than that of MP at every time-point $(\mathrm{p}<0.05)$, and than that of GP during the first $5 \mathrm{~h}$ after

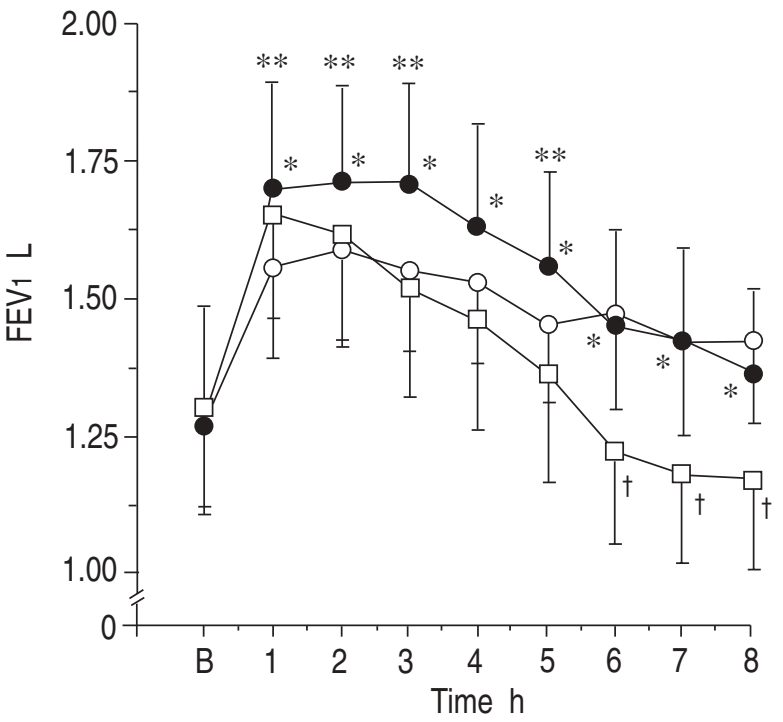

Fig. 1. - Increase in forced expiratory volume in one second (FEV1) from baseline (B) following inhalation of metaproterenol (MP - glycopyrrolate (GP $\longrightarrow-$ ), or their combination $(\mathrm{MP}+\mathrm{GP} \longrightarrow-$ ). Values are mean \pm SEM. B: baseline; *: $\mathrm{p}<0.05$ when compared with MP; **: $\mathrm{p}<0.05$ when compared with GP; $\uparrow: \mathrm{p}<0.05$ when compared with GP.

administration $(\mathrm{p}<0.05)$. The mean peak percentage increase in FEV1 over baseline was approximately $35 \%$ for the combination and $25 \%$ for each drug alone.

The spirometric responses for FVC are shown in figure 2. Overall, GP was more effective than MP $(\mathrm{p}=0.0280)$, and the combination of GP and MP was superior to MP $(p=0.0012)$ but as effective as GP $(p=0.197)$. Analysis at each time-point showed that the two drugs produced essentially similar improvements in FVC during the first $5 \mathrm{~h}$, with the peak effect being about $20 \%$ above baseline; the improvement in FVC was higher at $4 \mathrm{~h}$ and 6-8 $\mathrm{h}$ with GP than with MP $(\mathrm{p}<0.05)$. The combination of GP and MP produced a change in FVC that was greater than that of MP at $2-8 \mathrm{~h}(\mathrm{p}<0.05)$, and than that of GP only at 2, 3 and $5 \mathrm{~h}$ after administration $(\mathrm{p}<0.05)$. 


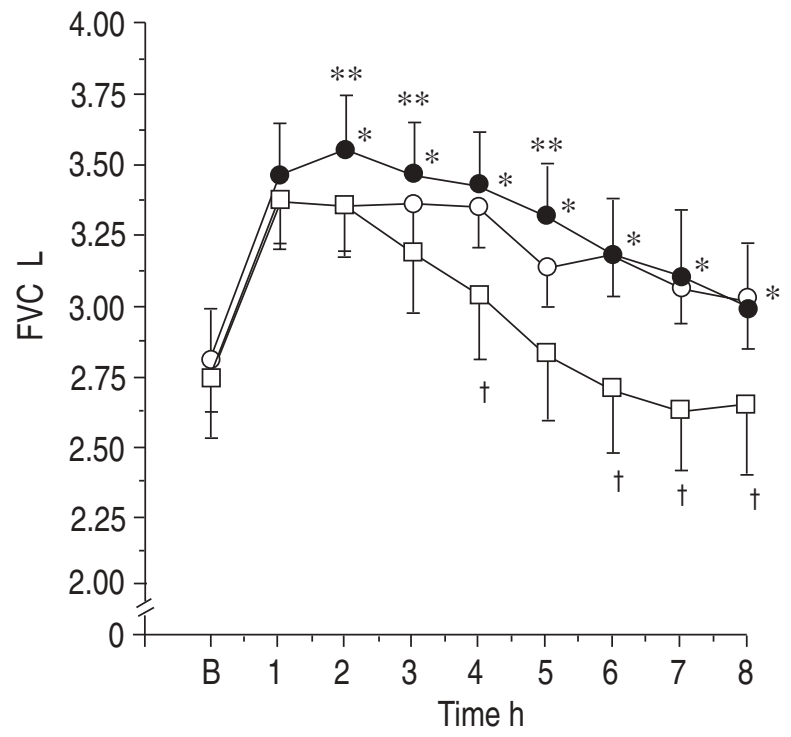

Fig. 2. - Increase in forced vital capacity (FVC) from baseline (B) after inhalation of metaproterenol (MP - - ), glycopyrrolate (GP $-2-$ ), or their combination $(\mathrm{MP}+\mathrm{GP} \longrightarrow$ ). Values are mean \pm SEM. B: baseline. *: $\mathrm{p}<0.05$ when compared with MP; **: $\mathrm{p}<0.05$ when compared with GP; $\dagger$ : $\mathrm{p}<0.05$ when compared with GP.

No significant changes in blood pressure or pulse rate were noted. One patient reported tremors after inhalation of MP.

\section{Discussion}

In this study, clinically stable patients with COPD, some still having marked reversibility, were given nebulized GP, MP, or a combination of the two drugs. We found that GP produced a bronchodilating effect similar to that of MP, but of considerably longer duration. When inhaled concurrently, the two drugs produced an additive bronchodilating effect that was mainly apparent during the effect of MP.

The bronchodilating effects of GP were first noted in normal volunteers. GAL et al. [1] showed that GP, given intravenously or as an aerosol, produced a significant increase in FEV1 which lasted up to $6 \mathrm{~h}$. Subsequent studies confirmed the prolonged bronchodilating effect of GP in asthma, some studies [3, 5] demonstrating a bronchodilator effect up to $12 \mathrm{~h}$. GILMAN et al. [2] also showed that the increase in FEV1 produced by GP was comparable to that of MP. The present study extends these previous observations to patients with stable COPD. As in studies with asthmatic patients, we found that the peak bronchodilating response of GP occurred within $1-2 \mathrm{~h}$, and the duration of action was $2-8 \mathrm{~h}$.

The dose of GP used in the present study was selected on the basis of our own experience and also on studies in normals and in patients with asthma. In a preliminary study in COPD patients [8], we found that inhalation of $0.5 \mathrm{mg}$ of GP produced a significant bronchodilation, yet smaller than that of $15 \mathrm{mg}$ of MP. SCHROECKENSTEIN et al. [5] found that GP dosages of 0.5 or $1.0 \mathrm{mg}$ produced equivalent bronchodilation. In a study comparing dose-response curves in normals, GaL et al. [1] found that the greater the dosage of GP the more sustained the bronchodilating effect. However, the duration of bronchodilation produced by GP dosages greater than $1.5 \mathrm{mg}$ was marginally better than that produced by a dose of $0.8 \mathrm{mg}$. Furthermore, the higher dosages were associated with more side-effects. GAL et al. [1], therefore, concluded that GP dosages of $1.0 \mathrm{mg}$ could be used effectively with virtually no side-effects.

Unlike previous studies in asthmatics, we evaluated whether the bronchodilator effects of GP could be potentiated by a beta-agonist. We found that the concurrent inhalation of GP and MP enhanced the bronchodilating effect produced by either agent alone by an additional $10 \%$ improvement over baseline. This additive effect was evident only during the first $5 \mathrm{~h}$ after administration, an interval equal to the duration of action of MP.

The effects of concurrent administration of anticholinergic and adrenergic agents have been extensively evaluated and the results are controversial. Some studies have found synergistic effect [9-15], whereas others have not [16-19]. The additive effect of the two agents could be explained on the basis of differences in the mechanism of bronchodilation; anticholinergics act through the parasympathetic system whereas beta-agonists act through the sympathetic system. An alternative explanation for the additive effects may be related to submaximal dosages used rather than to enhanced effectiveness of the combined treatment. In patients with stable COPD, Gross and SKORODIN [20] showed that addition of a betaagonist to large dosages of an anticholinergic agent did not augment bronchodilation produced by the anticholinergic agent alone. In another study, EASTON et al. [21] found that addition of a second agent does not improve bronchodilation if large dosages of either adrenergic or anticholinergic agent are used. A potential advantage of the combined regimen is that it may reduce toxicity caused by each agent.

In the present study, all patients had partially reversible obstruction as measured following inhalation of a beta-adrenergic agonist. The question then arises as to whether GP is effective in patients not responding to beta-agonists. Previous studies have shown that COPD patients who do not respond to beta-agonists usually respond to anticholinergic bronchodilators, such as atropine or ipratropium bromide [9, 22]. Thus, as with atropine or ipratropium, a therapeutic trial of GP might be useful in patients with irreversible obstruction.

In conclusion, we found that glycopyrrolate achieved the same degree of bronchodilation as metaproterenol and had a duration of action that was longer than that of metaproterenol alone. Further studies involving larger numbers of patients are needed to establish the bronchodilator efficacy, safety and optimal dosage of glycopyrrolate in COPD.

Acknowledgements: The authors thank F.D. McCool for reviewing the manuscript and M. Cohen for his assistance with the statistical analysis.

\section{References}

1. Gal TJ, Suratt PM, Lu JY. Glycopyrrolate and atropine inhalation: comparative effects on normal airway function. Am Rev Respir Dis 1984; 129: 871-873. 
2. Gilman MJ, Meyer L, Carter J, Slovis C. Comparison of aerosolized glycopyrrolate and metaproterenol in acute asthma. Chest 1990; 98: 1095-1098.

3. Walker FB, Kaiser DL, Kowal MB, Suratt PM. Prolonged effect of inhaled glycopyrrolate in asthma. Chest 1987; 91: 49-51.

4. Johnson BE, Suratt PM, Gal TJ, Wilhoit SC. Effect of inhaled glycopyrrolate and atropine in asthma. Chest 1984; 85: 325-328.

5. Schroeckestein DC, Bush RK, Chervinsky P, Busse WW. Twelve hour bronchodilation in asthma with a single aerosol dose of the anticholinergic compound glycopyrrolate. J Allergy Clin Immunol 1988; 82: 115-119.

6. Lung function testing: selection of reference values and interpretative strategies. Am Rev Respir Dis 1991; 144: 1202-1218.

7. Dixon WJ (Ed.). BMDP statistical software manual. Berkeley, CA, University of California Press, 1990; Vol. 2.

8. Komanapolli S, Fulambarker A, Tyler D, Vega D, Patel J, Tzelepis G. Effects of glycopyrrolate and metaproterenol alone and in combination in COPD. Am Rev Respir Dis 1993; 147 (4): A316 (Abstract).

9. Dougals NJ, Davidson I, Sudlow MF, Fleney D. Bronchodilatation and the site of airway resistance in severe chronic bronchitis. Thorax 1979; 34: 51-56.

10. Lightbody LM, Ingram CG, Legge JS, Johnston RN. Ipratropium bromide, salbutamol and prednisolone in bronchial asthma and chronic bronchitis. Br J Dis Chest 1978; 72: 181-186.

11. Koyama H, Nishimura K, Ikeda A, Izumi T. A comparison of the bronchodilating effects of oxitropium bromide and fenoterol in patients with chronic obstructive pulmonary disease. Chest 1993; 104: 1743-1747.

12. Less AW, Allan GW, Smith J. Nebulized ipratropium bromide and salbutamol in chronic bronchitis. $\mathrm{Br} \mathrm{J} \mathrm{Clin}$ Pract 1980; 3: 340-342.

13. Leitch AG, Hopkin JM, Ellis DA, Merchant S, McHardy
GJR. The effect of aerosol ipratropium bromide and salbutamol on exercise tolerance in chronic bronchitis. Thorax 1978; 33: 711-713.

14. Petrie GR, Palmer KNV. Comparison of aerosol ipratropium bromide and salbutamol in chronic bronchitis and asthma. Br Med J 1975; 1: 430-432.

15. Combivent Inhalation Aerosol Study Group. In chronic obstructive pulmonary disease, a combination of ipratropium and albuterol is more effective than either agent alone. Chest 1994; 105: 1411-1419.

16. Rebuck AS, Chapman KR, Abboud R, Paré PD, Kreisman $\mathrm{H}$, Wolkove N. Nebulized anticholinergic and sympathomimetic treatment of asthma and chronic obstructive airway disease in the emergency room. Am J Med 1987; 82: 59-64.

17. Karpel JP, Pesin J, Greenberg D, Gentry E. A comparison of the effects of ipratropium bromide and metaproterenol sulfate in acute exacerbations of COPD. Chest 1990; 98: 835-839.

18. Karpel JP. Bronchodilator responses to anticholinergic and beta-adrenergic agents in acute and stable COPD. Chest 1991; 99: 871-876.

19. Lloberes P, Ramis L, Montserrat JM, et al. Effect of three different bronchodilators during an exacerbation of chronic obstructive pulmonary disease. Eur Respir $J$ 1988; 1: 536-539.

20. Gross NJ, Skorodin MS. Role of the parasympathetic system in airway obstruction due to emphysema. $N$ Engl J Med 1984; 311: 421-425.

21. Easton PA, Jadue C, Dhigra S, Antonisen NR. A comparison of the bronchodilating effects of a beta ${ }_{2}$-adrenergic agent (albuterol) and an anticholinergic agent (ipratropium bromide), given by aerosol alone or in combination. N Engl J Med 1986; 315: 753-759.

22. Marini JJ, Lakshminarayan S. The effect of atropine inhalation in "irreversible" chronic bronchitis. Chest 1980; 77: 591-596. 